\title{
Preclinical and clinical experiences with the role of dopamine receptors in the treatment of pituitary adenomas
}

\author{
Diego Ferone, Rosario Pivonello ${ }^{1}$, Eugenia Resmini, Mara Boschetti, Alberto Rebora, Manuela Albertelli, \\ Valeria Albanese, Annamaria Colao ${ }^{1}$, Michael D Culler ${ }^{2}$ and Francesco Minuto \\ Department of Endocrinological and Medical Sciences and Center of Excellence for Biomedical Research, University of Genova, Genova, Italy, ${ }^{1}$ Department of \\ Molecular and Clinical Endocrinology and Oncology 'Federico II' University, Naples, Italy and ${ }^{2}$ Biomeasure Inc./IPSEN, Milford, Massachusetts, USA \\ (Correspondence should be addressed to Diego Ferone; Email: ferone@unige.it)
}

\begin{abstract}
Pituitary tumors can cause symptoms of mass effect and hormonal hypersecretion that can be reversed with surgical resection or debulking of the adenoma, radiotherapy, or medical treatment. Medical treatment is the primary choice for prolactinomas because dopamine agonists are very effective in the treatment of these tumors, with rates of control (tumor size reduction and hormone suppression) as high as $80-90 \%$ for microprolactinomas and $60-75 \%$ for macroprolactinomas. The function of dopamine receptors in other histotypes of pituitary adenoma is still debated. However, new insights into receptor physiology and the introduction of new clinically available, as well as experimental, compounds have reopened a potential role of dopaminergic drugs in the medical treatment of pituitary tumors. The differences between the effectiveness and the resistance to different dopaminergic agents, the new challenging results from clinical and experimental studies, as well as the future of dopamine agonists in the therapy of pituitary tumors are discussed.
\end{abstract}

European Journal of Endocrinology 156 S37-S43

\section{Introduction}

The therapeutic strategy for pituitary adenomas includes surgery, radiotherapy, and medical therapy. Therefore, a combination of treatments may be required to attain the therapeutic goal. Among the medications, dopamine agonists represent the first generation of effective drugs used in the treatment of pituitary tumors. The introduction of this class of compounds was based on the evidence that in the hypothalamic-pituitary system, the neurotransmitter/neuromodulator dopamine inhibits pituitary hormone secretion, in particular prolactin (PRL)- and proopiomelanocortin-derived hormones. It is well known that dopamine agonists, such as bromocriptine, pergolide, terguride, lisuride, quinagolide and cabergoline, can inhibit PRL secretion by binding to the $\mathrm{D}_{2}$ dopamine receptors $\left(\mathrm{D}_{2}\right)$ located on both normal and pituitary adenoma cells (1). Moreover, they can effectively decrease excessive PRL secretion, as well as the size of the tumor in patients with prolactinoma (2). Furthermore, dopamine agonists can also be used in the treatment of patients with other

This paper was presented at a symposium held at the Erasmus Medical Center, Rotterdam, The Netherlands, 2005. The symposium was jointly organized by LJ Hofland, Erasmus Medical Center, and A Colao, Federico II University of Naples, Italy. Ipsen partially supported the publication of these proceedings. pituitary tumor histotypes although less frequently. The major requirement for its use is that the tumor cells should express $\mathrm{D}_{2}$ receptors. Therefore, in addition to prolactinomas, targets of dopamine agonist therapy are somatotrope tumors, nonfunctioning pituitary tumors, corticotrope pituitary tumors including Nelson's syndrome, gonadotropinomas and thyrotropin-secreting pituitary tumors (2). Different dopaminergic agents have been introduced into clinical practice over the last decades, and the role of this group of compounds has been recently renewed due to the availability of novel clinical as well as experimental molecules, representing one of the most interesting future perspectives for the medical therapy of pituitary tumors.

\section{Dopamine receptors}

Dopamine receptors (DRs) belong to the family of $G$ protein coupled receptors and they modulate the activity of adenylate cyclases through $\mathrm{G}$ proteins. Based on their interaction with adenylate cyclase, the five known DRs are divided into two subfamilies: the $\mathrm{D}_{1}$ like $\left(D_{1}\right.$ and $\left.D_{5}\right)$ and the $D_{2}$-like $\left(D_{2}, D_{3}\right.$ and $\left.D_{4}\right)$ receptors. $\mathrm{D}_{1}$-like receptors stimulate adenylate cyclase activity through $\mathrm{G}_{\mathrm{s}}$ proteins, while $\mathrm{D}_{2}$-like receptors decrease intracellular cAMP accumulation through $\mathrm{G}_{\mathrm{i}} / \mathrm{G}_{\mathrm{o}}$ proteins (1). The $\mathrm{D}_{2}$ receptor exists in two 
different isoforms: long $\left(\mathrm{D}_{2 \text { long }}\right)$ and short $\left(\mathrm{D}_{2 \text { short }}\right)$. $\mathrm{D}_{2}$ isoforms differ in the presence or absence of a stretch of 29 amino acids in the third cytoplasmic loop, involved in G protein receptor coupling (1). The two $\mathrm{D}_{2}$ isoforms may be associated with different intracellular signaling transduction mechanisms and therefore elicit different effects after binding to dopamine agonists (1). The five DR subtypes have a different tissue distribution pattern and play multiple roles in various organs and tissues. The $\mathrm{D}_{2}$ receptor is expressed in the anterior and intermediate lobes of the pituitary gland, where it mediates the tonic inhibitory control of hypothalamic dopamine on PRL and MSH secretion respectively (1). In particular, $D_{2 \text { short }}$ and $\mathrm{D}_{2 \text { long }}$ receptor isoforms are expressed in both melanotrope and lactotrope cells, where the longer form is predominant. Moreover, subpopulations of lactotropes have been identified which express different $\mathrm{D}_{2 \text { long }} / \mathrm{D}_{2 \text { short }}$ mRNA ratios. The $\mathrm{D}_{4}$ receptor is also expressed in the anterior pituitary; however, its role is still unknown (1).

Multiple signal transduction mechanisms are activated by $\mathrm{D}_{2}$ receptors in the pituitary gland. In addition to the inhibition of adenylate cyclase, $D_{2}$ receptors, via G protein-dependent mechanisms, inhibit phosphatidylinositol metabolism, activate voltageactivated potassium and decrease voltage-activated L- and T-type calcium currents.

The presence of $\mathrm{D}_{2}$ receptors which mediate inhibition of PRL secretion by the anterior pituitary gland has led to the first and major therapeutic application of dopamine agonists in the treatment of hyperprolactinemia due to functional hypothalamus-pituitary alterations or the presence of PRL-secreting tumors. Indeed, $\mathrm{D}_{2}$ receptor agonists are the most effective pharmacological tools to normalize serum PRL levels in these patients (reviewed in Ref. 3). Furthermore, the major biochemical defects contributing to dopamine agonist resistance in prolactinomas seem to be either the decreased density or the absence of $\mathrm{D}_{2}$ receptors (1). In fact, mutations in the $\mathrm{D}_{2}$ receptor gene have not been observed in PRL- or GH/ PRL-secreting pituitary tumors (4).

Bromocriptine, one of the first generation dopamine agonists, has been widely used for the treatment of pituitary tumors. It binds both $\mathrm{D}_{1}$ and $\mathrm{D}_{2}$ receptors, whereas cabergoline and quinagolide are more selective for the $\mathrm{D}_{2}$ receptor. However the latter compounds have a longer duration of action and are better tolerated than bromocriptine (2).

Pituitary scintigraphy using in vivo $\mathrm{D}_{2}$ targeting agents may indicate the expression of DRs in pituitary tumors and select patients potentially responsive to treatment with dopamine agonists (5-7). However, it is an expensive technique and its value has been recently weakened, particularly for clinically nonfunctioning adenomas (NFAs; 8, 9). In spite of the limited significance in clinical practice, these data support the concept that the receptor pattern has a key role for the choice of the most appropriate treatment schedule and for a successful medical therapy (10). Whereas in vitro, besides ligand-binding and molecular biology techniques, availability of subtype-specific antibody to $\mathrm{D}_{2}$ seems to offer a new easier method to evaluate the receptor profile, at least in those pituitary adenomas that are unsuccessfully operated (11).

\section{Role of DRs in pituitary adenomas}

Prolactinomas Hyperprolactinemia is commonly found in both female and male patients with abnormal sexual and/or reproductive function, or with galactorrhea. If serum PRL levels are above $200 \mu \mathrm{g} / \mathrm{l}$, prolactinoma is the underlying cause; if the levels are lower, different diagnoses include drug interference, compression of the pituitary stalk by other pathology, hypothyroidism, renal failure, cirrhosis, chest wall lesions, or idiopathic hyperprolactinemia $(3,12)$. Prolactinomas account for $\sim 40 \%$ of all pituitary adenomas and are an important cause of hypogonadism and infertility. When a pituitary tumor is present, patients often have pressure symptoms in addition to endocrine dysfunction, such as headaches, visual field defects or cranial nerve deficits. The majority of patients with prolactinomas, both micro- and macro-, can be successfully treated with dopaminergic drugs as first-line treatment, resulting in normalization of PRL secretion and gonadal function and with significant tumor shrinkage in a high percentage of cases (3). Dopamine agonist therapy for PRL excess has been developed over the last three decades. The inhibition of cAMP levels is a key step in the inhibition of PRL release by dopamine; therefore, it is likely that all dopaminergic ergot derivatives share similar mechanisms of action. The earlier therapies such as bromocriptine have been virtually replaced now by the newer dopamine agonist cabergoline, which has the most favorable profile, followed by quinagolide. Moreover, it has been shown that shrinkage of macroprolactinoma during cabergoline treatment is greater in naive patients than in patients pre-treated with other dopamine agonists (13). Dopamine agonists reduce the size of prolactinomas by inducing a reduction in cell volume (through inhibition of gene transcription and PRL synthesis), as well as by causing perivascular fibrosis and partial cell necrosis. There may also be a true antimitotic effect of these drugs. Histologically, there is a reduction in secretory activity and cell size, an increase in immunoreactive PRL cellular content, and inhibition of exocytosis. Moreover, dopamine agonists also seem to possess proapoptotic capabilities in prolactinomas, even after short-term treatment (14). If PRL levels are well controlled with dopamine agonist therapy, gradual tapering of the dose to the lowest effective amount is recommended. In a 
number of cases, medication can be stopped after several years, particularly in patients treated with cabergoline showing normalization of PRL levels and no evidence of tumor during magnetic resonance imaging examination (15). In the small group of patients who do not respond to this treatment or who refuse long-term therapy, surgery is offered, as radiotherapy has only a limited value (3).

In general, prolactinomas exhibit varying degrees of responsiveness to the dopamine agonists, ranging from complete response at one end to total resistance at the other. The majority of patients found to be resistant to bromocriptine subsequently respond to cabergoline. Moreover, treatment with cabergoline offers a greater chance of obtaining permanent remission and successful withdrawal of medication, compared with treatment with bromocriptine (15).

The concept of dopamine agonist resistance must be distinguished from that of dopamine agonist intolerance, in which adverse effects play the most relevant role. The responsibility of true dopamine agonist resistance is with the lactotrope dopamine $\mathrm{D}_{2}$ receptor itself, mainly the reduced density of $\mathrm{D}_{2}$ receptors, whereas it is still unclear whether receptor alterations, leading to changes in affinity and/or in the downstream signaling effectors, are involved (3).

GH-secreting adenomas In the late 1970s, the introduction of DR agonists made it possible to reduce $\mathrm{GH}$ secretion from somatotropinomas for the first time. Therefore, dopamine agonists represent the first effective medical treatment for acromegaly $(12,16)$, until the availability of somatostatin analogs. Moreover, the role of dopaminergic agents in acromegaly has been recently renewed with the introduction of cabergoline and with the novel insights into DR pathophysiology.

The effectiveness of dopamine agonists is related to the expression of $\mathrm{D}_{2}$ receptor on a subset of somatotrope adenomas, and the presence of such receptors correlates with response to therapy. Advantages of these agents include the availability of an oral formulation and a lower cost compared with other medical options. Generally, bromocriptine normalizes IGF-I levels in about $10 \%$ of cases $(12,16)$. In a comparative study, long-term treatment with quinagolide or cabergoline or long-acting bromocriptine depot preparation caused a significant decrease in GH and IGF-I; however only quinagolide normalized circulating hormones, in $43.8 \%$ of treated patients (17). From this study, quinagolide apparently resulted as the most effective drug. However, the low dose of cabergoline and bromocriptine used limited the value of this comparative study between the three dopaminergic drugs. The dosage of bromocriptine required to achieve IGF-I normalization is often high (20-40 mg/day) and usually poorly tolerated because of gastrointestinal discomforts or headache. As a result, the role of bromocriptine seems to be limited in the treatment of acromegaly. Conversely, in another study on a larger population, higher doses of cabergoline normalized IGF-I in $39 \%$ of patients with acromegaly, but improved responses were detected primarily in those patients with slight IGF-I elevations and concomitant hypersecretion of PRL (18). Cabergoline seems to be more effective than other dopamine agonists in acromegaly not only in normalizing hormone levels, but also in inducing significant tumor shrinkage (19). The co-secretion of PRL (in $\sim 40 \%$ of adenomas from acromegalic patients) has often been suggested to predict improved response to dopamine agonists. However, more recent evidences are driving down the potential role of both circulating PRL levels and PRL positivity at immunohistochemistry in discriminating patients with a better response to dopaminergic drugs (20). Once again, the GH-IGF-I-lowering effect of dopamine agonist treatment can be accounted for by the expression and binding of the drug to $\mathrm{D}_{2}$ receptors, present not only in mixed GH/PRL tumor or somatomammotrope adenomas, but also in $30 \%$ of adenomatous 'pure' GH-secreting cells (20). Indeed, we have recently demonstrated in a large series of tumors from acromegalic patients a positive correlation between $\mathrm{D}_{2}$ expression and the sensitivity of GH and PRL secretion to quinagolide, as well as between somatostatin receptor $2 \mathrm{~A}$ expression and the sensitivity of GH and IGF-I secretion to somatostatin analog treatment. Conversely, the presence of PRL was not correlated with the tumor sensitivity to dopamine agonists, suggesting that the response to therapy might be affected by other elements $(21,22)$. This finding is in line with the evidence reported by Trouillas et al. using five lineages of SMtTW tumors that are representative of the most frequent tumors encountered in human pituitary pathology (23). These authors found a full concordance between tumor responses to bromocriptine and the expression of $\mathrm{D}_{2}$ receptor by the tumors. They also identified a tumor lineage with a malignant phenotype, secreting high amounts of PRL and presenting a resistance to bromocriptine, supporting the idea that dopamine agonist-resistant prolactinomas are aggressive tumors (23).

The usefulness of the association of dopamine agonists plus somatostatin analogs has been clearly demonstrated by several studies and is extensively reviewed by Colao et al. in another article of the present issue.

Clinically nonfunctioning adenomas NFAs are the most prevalent form of pituitary macroadenomas. They are devoid of a specific clinical syndrome related to hormonal hypersecretion and, hence, most patients are diagnosed late in the course of their disease, when the tumor is already large enough to cause mass-related signs and symptoms. Surgery is the first line of treatment, but unfortunately it is not curative in the majority of patients, even in the best neurosurgical centers. Radiotherapy is the only modality shown to be effective in the prevention of residual tumor growth. However, it is 
contraindicated in several cases and hypopituitarism is often recorded after radiation therapy.

The characterization and classification of this large and assorted group of tumors has significantly changed in the last few years, thanks to the availability of more sensitive techniques showing that the majority of these tumors indeed secrete FSH and/or LH or their respective $\alpha$-and $\beta$-subunits. However, secretion by these tumors is minimal or inefficient and the clinical behavior is that of an inactive tumor. Gonadotrope adenomas account for $10-15 \%$ of all pituitary adenomas, whereas $5-10 \%$ of all tumors are truly nonfunctional and are referred to as null cell adenomas (24). When studied in vivo, gonadotrope adenomas are identified on the basis of hypersecretion of FSH or LH, $\alpha$ - or $\beta$-subunit in the basal state or after dynamic stimulation with TRH. In vitro studies performed on surgically resected tumor tissue (immunohistochemistry or molecular biological techniques) have allowed a broader characterization of these adenomas showing positive staining but no measurable hormone secretion in some tumors (25). Therefore, silent corticotrope and somatotrope adenomas have been easily recognized as well (25). Ligandbinding studies and scintigraphic evaluations have previously shown the presence of somatostatin as well as dopamine-binding sites (mainly $\mathrm{D}_{2}$ receptor) in NFAs (5-7). More recently, sophisticated techniques have confirmed the heterogeneous expression of DRs in NFAs, and the effects of dopamine agonists in these tumors were investigated both in vivo and in vitro (26, 27). Conflicting results have been reported with respect to the effect of dopamine agonists on the growth of NFAs. In some clinical studies, no effect on the tumor size could be found, whereas in others tumor shrinkage was reported in up to $20 \%$ of the patients (28). In particular, long-term treatment of patients with NFA with high doses of quinagolide could not prevent progressive increase in tumor size in most patients, despite persistent suppression of hormone secretion (29). In addition, Renner et al. have suggested for the first time that the presence of the $\mathrm{D}_{2 \text { short }}$ isoform in the NFAs improves the growth-suppressive response to bromocriptine in vitro (26). This finding has been subsequently confirmed in a large series of cases evaluated in vitro for the receptor content, demonstrating $\mathrm{D}_{2}$ receptor expression in nearly $70 \%$ of cases, and tested in vivo for the sensitivity to cabergoline (27). The expression of $\mathrm{D}_{2 \text { short }}$ rather than $\mathrm{D}_{2 \text { long }}$ isoform was found to be associated with the most favorable response of the tumor to cabergoline treatment (27). More recently, dopamine agonist therapy has been found to be associated with a decreased prevalence of residual tumor enlargement in patients with NFAs, particularly when treatment was initiated before the detection of tumor remnant growth (30). These authors suggested the routine use of dopaminergic drugs to prevent residual mass expansion in patients unsuccessfully operated for NFAs (30).
Recently, a hybrid somatostatin/dopamine molecule, BIM-23A387, has been tested in vitro in cultures of NFAs, where it affected the viability of some, but not all, pituitary adenoma cells (31). The chimeric compound exerted roughly similar inhibitory effects compared with bromocriptine (31). We have also tested two somatostatin/dopamine hybrid compounds in different series of pituitary adenomas (Fig. 1). Preliminary data seem to confirm the higher potency of these new chimeric molecules compared with the clinically available dopamine agonists and somatostatin analogs, particularly in inhibiting hormone secretion in cell cultures of selected NFAs and GH-secreting pituitary adenomas (Ferone et al. unpublished observations).

\section{Adrenocorticotropin (ACTH)- and thyrotropin} (TSH)-secreting adenomas Treatment with bromocriptine has been also investigated in ACTH-secreting or corticotrope pituitary tumors, although with controversial results (32-34). However, the first study evaluating DR expression and the effect of cabergoline treatment in controlling the ACTH and cortisol

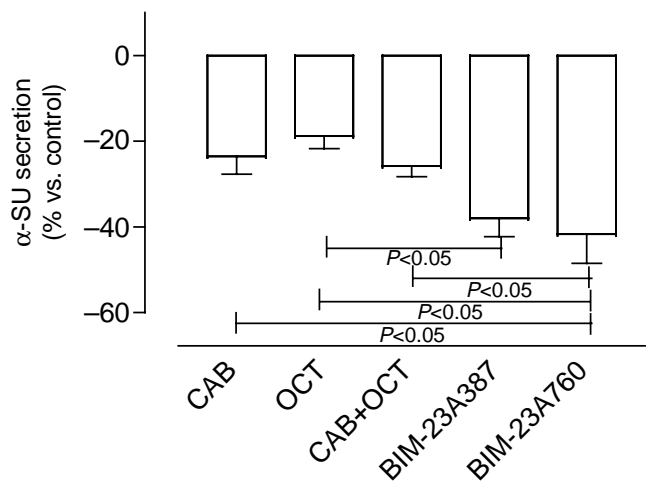

Figure 1 In vitro effects on $\alpha$-subunit ( $\alpha$-SU) secretion of cabergoline $(C A B)$, octreotide, (OCT), octreotide plus cabergoline (OCT+ CAB), BIM-23A387 and BIM-23A760 in primary cultures derived from three patients with clinically nonfunctioning pituitary adenomas. Cell suspensions of the pituitary adenoma tissues were prepared by enzymatic dissociation with collagenase. For shortterm incubation of monolayer cultures, the dissociated cells were plated onto collagen-coated 48-well plates (Costar, Cambridge, MA, USA) at a density of $10^{4}$ cells/well per $1 \mathrm{ml}$ culture medium to study hormone secretion. After 2 days, test substances were added in fresh medium at concentrations of $10^{-8} \mathrm{M}$, and at the end of $6-\mathrm{h}$ incubation, the medium was removed and centrifuged for $5 \mathrm{~min}$ at $600 \mathrm{~g}$. The supernatant was collected and stored at $-20^{\circ} \mathrm{C}$ until the determination of $\alpha$-subunit concentration.

$\alpha$-Subunit immunoreactivity was measured in the medium from cultured pituitary cells incubated with or without the abovementioned drugs (conditioned media). Hormone assays were performed in duplicate after appropriate sample dilutions of conditioned medium from treated cells. Results were obtained by determining the mean value among four replicates. Data are expressed as mean \pm S.E.M. BIM compounds were provided by Biomeasure, Inc. (Milford, MA, USA). BIM-23A387 and BIM23A760 are chimeric molecules that combine structural elements of both somatostatin and dopamine and retain affinity for both $\mathrm{sst}_{2}$ and $D_{2}$, and $s t_{2}, s_{5}$, and $D_{2}$ respectively (41). 
hypersecretion associated with corticotrope pituitary tumors has shown that the cabergoline-responsive cases were associated with $\mathrm{D}_{2}$ expression, whereas almost all cases not responsive to cabergoline showed absent $D_{2}$ expression (11). In this study, functional $\mathrm{D}_{2}$ receptors were expressed in $\sim 80 \%$ of corticotrope pituitary tumors, and the effectiveness of cabergoline in normalizing cortisol secretion in $40 \%$ of cases supports its therapeutic use in the management of persistent and/or recurrent Cushing's disease (11). The successful rates observed with bromocriptine in an early study (32) and with cabergoline in a recent one (11) is, therefore, based on the presence of functional $\mathrm{D}_{2}$ receptors on corticotropes. However, the different molecular, biochemical and pharmacological properties of cabergoline, particularly the higher specificity and affinity for $\mathrm{D}_{2}$ receptor and the longer duration of action, make the latter dopaminergic drug preferable to bromocriptine (35).

A dramatic tumor shrinkage has been also reported in a case of silent corticotrope tumor during cabergoline therapy (36). The in vitro studies on tumor tissue from the adenoma provided evidence of $D_{2}$ receptor expression within the tumor with an intensity comparable to that found in control prolactinomas (36). Similarly, treatment with cabergoline for one year induced normalization of plasma ACTH levels and disappearance of the pituitary tumor in a patient with Nelson's syndrome (37). The direct effect exerted by cabergoline treatment on the remission of Nelson's syndrome was proven by treatment withdrawal, showing a significant increase in ACTH levels after 3 months, suggesting that cabergoline may be a valid therapeutic alternative in this syndrome as well (37).

The presence of DRs in TSH-secreting adenomas has represented the rationale for therapeutic trials with dopamine agonists such as bromocriptine and cabergoline. Several studies have shown a large heterogeneity of TSH responses to dopaminergic agents either in primary cultures or in vivo (38). From a clinical viewpoint, dopamine agonists and cabergoline in particular have been employed in some TSH-secreting adenomas with variable results, positive effects being mainly observed in some patients with mixed PRL/TSH adenoma, whereas tumor shrinkage was documented in few cases (38).

The effects of dopamine agonists should be re-evaluated in light of the demonstration of heterodimerization of somatostatin receptor subtype 5 and dopamine $\mathrm{D}_{2}$ receptor (39). This phenomenon also seems to be linked with an enhanced functional activity of these receptor dimers (39). Indeed, the above-mentioned new hybrid compounds, that contain structural elements of both somatostatin and dopamine and retains potent selective agonist activity at both the somatostatin and DRs, displayed a higher potency compared with classical analogs in inhibiting hormone secretion and controlling cell proliferation in different cell models in vitro, including pituitary adenomas $(40,41)$. Receptor characterization will be necessary to understand the mechanisms regulating the response to medical therapy, particularly considering the future availability of these compounds (new somatostatin analogs and chimeric molecules) with specific receptor-binding profiles.

\section{Conclusions}

During recent years, the role of DRs in pituitary adenomas has been restored not only in light of the new insights into receptor pathophysiology, but also due to the availability of novel sophisticated technologies that are able to reveal novel potential mechanisms of action. The inhibitory effects of dopamine agonists on pituitary cells are mainly mediated through $\mathrm{D}_{2}$ receptors. On the other hand, other receptor subtypes have been detected at the pituitary level and the interaction of DRs with other neuropeptide receptors may reopen the discussion on the medical therapy of pituitary adenomas $(27,39-41)$. Dopamine agonists inhibit hormone release and induce tumor shrinkage in most PRL-secreting adenomas, whereas in other adenoma types such effects are less represented. Studies on $\mathrm{D}_{2}$ gene expression in different types of pituitary adenomas showed a variable $\mathrm{D}_{2}$ expression localized in the cytoplasm and nuclei of a large number of adenomas; however, the significance of nuclear localization of $\mathrm{D}_{2}$ protein remains unclear (42). Moreover, recent preliminary data suggest that both isoforms of dopamine $\mathrm{D}_{2}$ receptors are involved in the signaling pathways involved in the antiproliferation and cell death in pituitary tumor cells, possibly through p38 MAPK and ERK activation (43). The complete characterization and definition of the molecular basis of these signaling pathways may allow the mechanisms of the dopaminergic control of cell proliferation and cell death to be understood, particularly in pituitary tumors. Moreover, it is of interest to know whether the inclusion of the dopaminergic moiety in new somatostatin analogs could result in prolonged pharmacological properties of these chimeric molecules, or even activate alternative intracellular signaling pathways involved in the control of cell growth (40). Further studies on receptor expression and functionality in a larger population of patients with pituitary tumors are needed to better define patients who could benefit from dopamine agonists as a therapeutic option for pituitary adenomas.

\section{Acknowledgements}

This study was partially supported by grants from MIUR (2002067251-001), from the University of Genova, and by an educational grant from the CARIGE Foundation. 


\section{References}

1 Missale C, Nash SR, Robinson SW, Jaber M \& Caron MG. Dopamine receptors: from structure to function. Physiological Reviews 1998 78 189-225.

2 Ivan G, Szigeti-Csucs N, Olah M, Nagy GM \& Goth MI. Treatment of pituitary tumors: dopamine agonists. Endocrine $2005 \mathbf{2 8}$ 101-110.

3 Gillam MP, Molitch ME, Lombardi G \& Colao A. Advances in the treatment of prolactinomas. Endocrine Review 200627 485-534.

4 Friedman E, Adams EF, Hoog A, Gejman PV, Carson E, Larsson C, De Marco L, Werner S, Fahlbusch R \& Nordenskjold M. Normal structural dopamine type 2 receptor gene in prolactin-secreting and other pituitary tumors. Journal of Clinical Endocrinology and Metabolism $1994 \mathbf{7 8}$ 568-574.

5 de Herder WW, Reijs AE, Kwekkeboom DJ, Hofland LJ, Nobels FR, Oei HY, Krenning EP \& Lamberts SW. In vivo imaging of pituitary tumors using a radiolabelled dopamine D2 receptor radioligand. Clinical Endocrinology 199646 755-767.

6 Ferone D, Lastoria S, Colao A, Varrella P, Cerbone G, Acampa W, Merola B, Salvatore M \& Lombardi G. Correlation of scintigraphic results using 123I-Methoxybenzamide with hormone levels and tumor size response to quinagolide in patients with pituitary adenomas. Journal of Clinical Endocrinology and Metabolism 1998 $83248-252$

7 de Herder WW, Reijs AE, de Swart J, Kaandorp Y, Lamberts SW. Krenning EP \& Kwekkeboom DJ. Comparison of iodine-123 epidepride and iodine-123 IBZM for dopamine D2 receptor imaging in clinically non-functioning pituitary macroadenomas and macroprolactinomas. European Journal of Nuclear Medicine 199926 46-50.

8 de Herder WW, Reijs AEM, Feelders RA, van Aken MO, Krenning EP, Tanghe HLJ, van der Lely AJ \& Kwekkeboom DJ. Dopamine agonist therapy of clinically non-functioning pituitary macroadenomas. Is there a role for 123I-epidepride dopamine D2 receptor imaging? European Journal of Endocrinology 2006155 1-8.

9 de Herder WW, Reijs AEM, Feelders RA, van Aken M, Krenning EP, van der Lely AJ \& Kwekkeboom DJ. Diagnostic imaging of dopamine receptors in pituitary adenomas. European Journal of Endocrinology $2007 \mathbf{1 5 6}$ S53-S56.

10 Ferone D, Pivonello R, Lastoria S, Faggiano A, Del Basso de Caro ML, Cappabianca P, Lombardi G \& Colao A. In vivo and in vitro effects of octreotide, quinagolide and cabergoline in four hyperprolactinaemic acromegalics: correlation with somatostatin and dopamine D2 receptor scintigraphy. Clinical Endocrinology 200154 469-477.

11 Pivonello R, Ferone D, de Herder WW, Kros JM, De Caro ML, Arvigo M, Annunziato L, Lombardi G, Colao A, Hofland LJ \& Lamberts SW. Dopamine receptor expression and function in corticotroph pituitary tumors. Journal of Clinical Endocrinology and Metabolism 200489 2452-2462.

12 Colao A \& Lombardi G. Growth-hormone and prolactin excess. Lancet 1998352 1455-1461.

13 Colao A, Di Sarno A, Landi ML, Scavuzzo F, Cappabianca P, Pivonello R, Volpe R, Di Salle F, Cirillo S, Annunziato L \& Lombardi G. Macroprolactinoma shrinkage during cabergoline treatment is greater in naive patients than in patients pretreated with other dopamine agonists: a prospective study in 110 patients. Journal of Clinical Endocrinology and Metabolism $2000852247-2252$.

14 Kontogeorgos G, Horvath E, Kovacs K, Coire C, Lloyd RV, Scheithauer BW \& Smyth HS. Morphologic changes of prolactinproducing pituitary adenomas after short treatment with dopamine agonists. Acta Neuropathologica 2006111 46-52.

15 Colao A, Di Sarno A, Cappabianca P, Di Somma C, Pivonello R \& Lombardi G. Withdrawal of long-term cabergoline therapy for tumoral and nontumoral hyperprolactinemia. New England Journal of Medicine $20033492023-2033$.

16 Muller AF \& van der Lely AJ. Pharmacological therapy for acromegaly: a critical review. Drugs $2004641817-1838$.
17 Colao A, Ferone D, Marzullo P, Di Sarno A, Cerbone G, Sarnacchiaro F, Cirillo S, Merola B \& Lombardi G. Effect of different dopaminergic agents in the treatment of acromegaly. Journal of Clinical Endocrinology and Metabolism 199782 518-523.

18 Abs R, Verhelst J, Maiter D, Van Acker K, Nobels F, Coolens JL Mahler $\mathrm{C} \&$ Beckers A. Cabergoline in the treatment of acromegaly: a study in 64 patients. Journal of Clinical Endocrinology and Metabolism $1998 \mathbf{8 3} 374-378$.

19 Cozzi R, Attanasio R, Barausse M, Dallabonzana D, Orlandi P, Da Re N, Branca V, Oppizzi G \& Gelli D. Cabergoline in acromegaly: a renewed role for dopamine agonist treatment? European Journal of Endocrinology $1998139516-521$.

20 Cozzi R, Attanasio R, Lodrini S \& Lasio G. Cabergoline addition to depot somatostatin analogues in resistant acromegalic patients: efficacy and lack of predictive value of prolactin status. Clinical Endocrinology 200461 209-215.

21 Ferone D, Pivonello R, Lastoria S, Faggiano A, Del Basso de Caro ML, Cappabianca P, Lombardi G \& Colao A. In vivo and in vitro effects of octreotide, quinagolide and cabergoline in four hyperprolactinaemic acromegalics: correlation with somatostatin and dopamine D2 receptor scintigraphy. Clinical Endocrinology $2001 \mathbf{5 4} 469-477$.

22 Ferone D, de Herder WW, Pivonello R, Kros JM, de Jong T, van Koetsveld PM, Colao A, Lamberts SWJ \& Hofland LJ. Immunohistochemical evaluation of somatostatin sst2A and dopamine D2 receptors in pituitary adenomas of acromegalics: correlation with response to somatostatin analogs and dopamine agonists and electron microscopy study. Journal of Endocrinological Investigation $2003 \mathbf{2 6} 88$

23 Trouillas J, Chevallier P, Remy C, Rajas F, Cohen R, Calle A, Hooghe-Peters EL \& Rousset B. Differential actions of the dopamine agonist bromocriptine on growth of SMtTW tumors exhibiting a prolactin and/or a somatotroph cell phenotype: relation to dopamine D2 receptor expression. Endocrinology $199914013-21$.

24 Kontogeorgos G. Classification and pathology of pituitary tumors. Endocrine 200528 27-35.

25 Arafah BM \& Nasrallah MP. Pituitary tumors: pathophysiology, clinical manifestations and management. Endocrine Related Cancer 20018 287-305.

26 Renner U, Arzberger T, Pagotto U, Leimgruber S, Uhl E, Muller A, Lange M, Weindl A \& Stalla GK. Heterogeneous dopamine D2 receptor subtype messenger ribonucleic acid expression in clinically nonfunctioning pituitary adenomas. Journal of Clinical Endocrinology and Metabolism 199883 1368-1375.

27 Pivonello R, Matrone C, Filippella M, Cavallo LM, Di Somma C, Cappabianca P, Colao A, Annunziato L \& Lombardi G. Dopamine receptor expression and function in clinically nonfunctioning pituitary tumors: comparison with the effectiveness of cabergoline treatment. Journal of Clinical Endocrinology and Metabolism 2004 89 1674-1683.

28 Bevan JS, Webster J, Burke CW \& Scanlon MF. Dopamine agonists and pituitary tumor shrinkage. Endocrine Reviews 199213 220-240.

29 Nobels FR, de Herder WW, van den Brink WM, Kwekkeboom DJ, Hofland LJ, Zuyderwijk J, de Jong FH \& Lamberts SW. Long-term treatment with the dopamine agonist quinagolide of patients with clinically non-functioning pituitary adenoma. European Journal of Endocrinology 2000143 615-621.

30 Greenman Y, Tordjman K, Osher E, Veshchev I, Shenkerman G, Reider-Groswasser II, Segev Y, Ouaknine G \& Stern N. Postoperative treatment of clinically nonfunctioning pituitary adenomas with dopamine agonists decreases tumour remnant growth. Clinical Endocrinology 200563 39-44.

31 Gruszka A, Kunert-Radek J, Radek J, Pisarek H, Taylor J, Dong JZ, Culler MD \& Pawlikowski M. The effect of selective sst1, sst2, sst5 somatostatin receptors agonists, a somatostatin/dopamine (SST/DA) chimera and bromocriptine on the "clinically nonfunctioning' pituitary adenomas in vitro. Life Sciences $2006 \mathbf{7 8}$ 689-693.

32 Shimon I \& Melmed S. Management of pituitary tumors. Annals of Internal Medicine 1998129 472-483. 
33 Lamberts SW, Klijn JG, de Quijada M, Timmermans HA, Uitterlinden P, de Jong FH \& Birkenhager JC. The mechanism of the suppressive action of bromocriptine on adrenocorticotropin secretion in patients with Cushing's disease and Nelson's syndrome. Journal of Clinical Endocrinology and Metabolism 1980 $51307-311$.

34 Miller JW \& Crapo L. The medical treatment of Cushing's syndrome. Endocrine Reviews 199314 443-458.

35 Colao A, Lombardi G \& Annunziato L. Cabergoline. Expert Opinion on Pharmacotherapy 20001 555-574.

36 Petrossians P, Ronci N, Valdes Socin H, Kalife A, Stevenaert A, Bloch B. Tabarin A \& Beckers A. ACTH silent adenoma shrinking under cabergoline. European Journal of Endocrinology 2001 144 51-57.

37 Pivonello R, Faggiano A, Di Salle F, Filippella M, Lombardi G \& Colao A. Complete remission of Nelson's syndrome after 1-year treatment with cabergoline. Journal of Endocrinological Investigation 199922 860-865.

38 Beck-Peccoz P \& Persani L. Medical management of thyrotropinsecreting pituitary adenomas. Pituitary 20025 83-88.

39 Rocheville M, Lange DC, Kumar U, Patel SC, Patel RC \& Patel YC. Receptors for dopamine and somatostatin: formation of heterooligomers with enhanced functional activity. Science $2000 \mathbf{2 8 8}$ 154-157.
40 Saveanu A, Gunz G, Guillen S, Dufour H, Culler MD \& Jaquet P. Somatostatin and dopamine-somatostatin multiple ligands directed towards somatostatin and dopamine receptors in pituitary adenomas. Neuroendocrinology $200683258-263$.

41 Ferone D, Arvigo M, Semino C, Jaquet P, Saveanu A, Taylor JE, Moreau JP, Culler MD, Albertelli M, Minuto F \& Barreca A. Somatostatin and dopamine receptor expression in lung carcinoma cells and effects of chimeric somatostatin-dopamine molecules on cell proliferation. American Journal of Physiology Endocrinology and Metabolism 2005289 E1044-E1050.

42 Stefaneanu L, Kovacs K, Horvath E, Buchfelder M, Fahlbusch R \& Lancranjan L. Dopamine D2 receptor gene expression in human adenohypophysial adenomas. Endocrine $2001 \quad 14$ 329-336.

43 An JJ, Cho SR, Jeong DW, Park KW, Ahn YS \& Baik JH. Antiproliferative effects and cell death mediated by two isoforms of dopamine D2 receptors in pituitary tumor cells. Molecular and Cellular Endocrinology 2003206 49-62.

Received 29 January 2007

Accepted 30 January 2007 